\title{
Un cuarto de siglo de Contrastes (y antes ocho años más)
}

\section{A quarter of a century of Contrastes (plus the previous eight years)}

\author{
PASCUAL F. MARTÍNEZ-FREIRE \\ Director Honorario de Contrastes. \\ Revista Internacional de Filosofía
}

El PRESENTE NúMERo 3 del volumen XXV (2020) de Contrastes constituye el número de cierre del año vigésimo quinto de esta revista de Filosofía, que se puso en marcha en el año 1996.

Sin embargo la revista Contrastes no surgió de la nada, ya que fue la sucesora de la revista Philosophica Malacitana, ambas editadas por el Departamento de Filosofía de la Universidad de Málaga.

En resumen, los datos históricos pertinentes son los siguientes.

En 1988 apareció Philosophica Malacitana, que se iniciaba con un artículo de la filósofa malagueña María Zambrano, por entonces felizmente viva. Su Consejo de Dirección estaba formado por Pascual Martínez-Freire, como director, Juan Fernando Ortega Muñoz y José Rubio Carracedo, secretarios, y Antonio Javier Diéguez Lucena, secretario administrativo. Esta revista del Departamento de Filosofía de la Universidad de Málaga pervivió ocho años, hasta 1995, con algún cambio en el Consejo de Dirección, a saber, desde 1991 a 1995 José Rubio Carracedo pasó a Director mientras que Pascual Martínez-Freire pasó a secretario, y asimismo Antonio Javier Diéguez Lucena fue sustituido, como secretario administrativo, por Luis de Santiago Guervós.

Philosophica Malacitana publicaba un volumen anual con un solo número, aunque desde 1993 a 1995 se publicó además un suplemento monográfico por año. Estos suplementos fueron sucesivamente "El giro posmoderno",

(C) Contrastes. Revista Internacional de Filosofía, vol. XXV Nº3 (2020), pp. 7-10. ISSN: 1136-4076 
editado por José Rubio, "Actualidad de Nietzsche en el 150 aniversario de su nacimiento", editado por Luis de Santiago, y "Filosofía y ciencias cognitivas", editado por Pascual Martínez-Freire.

Tras el acuerdo correspondiente del Consejo del Departamento de Filosofía de la Universidad de Málaga, Philosophica Malacitana fue sustituida en 1996 por Contrastes. Revista Interdisciplinar de Filosofia, recogiendo así en el título la participación en la revista de las cuatro áreas de conocimiento del Departamento, a saber, Filosofía, Lógica y Filosofía de la Ciencia, Filosofía Moral y Política y también Estética y Teoría de las Artes. Su Consejo de Dirección estaba formado por José Rubio Carracedo como director, Pascual Martínez-Freire y Juan Fernando Ortega Muñoz como subdirectores, José María Rosales Jaime como secretario de redacción, y Luis de Santiago Guervós como secretario de administración.

Desde el volumen del año 2001 hasta 2006 José María Rosales fue sustituido por Manuel Toscano Méndez como secretario de redacción. Asimismo desde el volumen del año 2005 Juan Fernando Ortega Muñoz dejó de ser subdirector.

En el volumen VIII de 2003 la revista pasó a su denominación actual, es decir, Contrastes. Revista Internacional de Filosofía, cambiando el término "interdisciplinar" por el término "internacional", a fin de reflejar su cada vez mayor carácter internacional.

La revista Contrastes, desde su inicio en 1996, ha publicado un suplemento monográfico por año, además del volumen ordinario. A su vez, el volumen ordinario, a partir de 2008, consta de dos números.

En el volumen XIV de 2009 el Consejo de Dirección fue notablemente modificado. Pascual Martínez-Freire pasó a director (por cese de José Rubio), Juan A. García González fue nombrado vicedirector, Antonio Diéguez Lucena era el secretario de redacción (ya desde el año anterior) y, finalmente, Juan José Padial Benticuaga fue nombrado secretario de administración (por cese de Luis de Santiago).

Una nueva modificación en el Consejo de Dirección de Contrastes tuvo lugar en el volumen XVIII de 2013. Pascual Martínez-Freire siguió como director, pero Antonio Diéguez Lucena pasó a director asociado, continuando Juan A. García González como vicedirector; a su vez, José María Atencia Páez fue nombrado secretario de redacción, siguiendo Juan José Padial Benticuaga como secretario de administración.

Tras algunos cambios menores en los últimos años, actualmente el Consejo de Dirección es el siguiente: Pascual Martínez-Freire es el director honorario y Antonio Diéguez Lucena es el director; a su vez, Juan José Padial es el vicedirector primero mientras que Alejandro Rojas Jiménez es el vicedirector segundo; y finalmente Gloria Luque Moya es la secretaria de redacción. 
Aunque estos datos históricos resultan interesantes, más importante es destacar la temática de la revista Contrastes. Se trata de una revista de Filosofía que atiende a los asuntos y temas de las cuatro áreas de conocimiento que componen el Departamento de Filosofía de la Universidad de Málaga, a saber, Filosofía, Lógica y Filosofía de la Ciencia, Filosofía Moral y Política y también Estética y Teoría de las Artes.

Por supuesto, además del Consejo de Dirección, la revista Contrastes dispone de un Consejo Editorial, sobre el que recae básicamente la evaluación de los originales enviados a la revista para su publicación. Actualmente este Consejo Editorial consta de dieciocho especialistas de las cuatro áreas mencionadas, de los cuales seis pertenecen a la Universidad de Málaga y doce a otras Universidades.

También dispone Contrastes de un Consejo Asesor, que proporciona asesoría y respaldo internacional a la revista. Actualmente está formado por dieciséis personalidades filosóficas de España y del extranjero de las cuatro áreas filosóficas mencionadas.

Tal como señalan las normas de publicación, Contrastes sólo admite trabajos originales, preferentemente en castellano, inglés, francés, alemán y cualquier lengua romance. De hecho casi todos los artículos están en castellano. Y es de resaltar la abundante contribución de autores hispanoamericanos.

En cuanto a la evaluación de los trabajos enviados para su publicación es una evaluación externa y por pares, para la cual no sólo se recurre a los miembros de los tres Consejos de la revista (Dirección, Editorial y Asesor) sino también a otros especialistas de alto rango académico, garantizando que los evaluadores no pertenezcan a la misma Universidad que el autor. Por supuesto, la evaluación es ciega (ignorando el evaluador la identidad del autor) y puede ser doble o triple.

El índice de aceptación de Contrastes es bueno. Como ejemplo, cabe destacar que Latindex (Sistema Regional de Información en Línea para Revistas Científicas de América Latina, el Caribe, España y Portugal) considera que la revista Contrastes cumple las treinta y tres características exigibles con cero no cumplidas.

Asimismo la FECYT (Fundación Española para la Ciencia y la Tecnología) ha otorgado a la revista Contrastes su sello de calidad en cinco convocatorias seguidas, desde 2016 a 2021.

Finalmente cabe destacar que, desde el volumen XVI de 2011, la revista Contrastes tiene firmado un contrato con EBSCO Publishing para su difusión internacional.

Para terminar esta nota conmemorativa del cuarto de siglo de Contrastes (más los ocho años previos de su predecesora Philosophica Malacitana), me parece obligado expresar el reconocimiento y agradecimiento a los miembros, 
en diversos momentos, tanto del Consejo de Dirección, como del Consejo Editorial y del Consejo Asesor. También debe agradecerse y reconocerse la labor de los evaluadores externos. Y finalmente, last but not least, el agradecimiento de estos treinta y tres años de revista del Departamento de Filosofía de la Universidad de Málaga se dirige de modo muy especial a los autores de los trabajos publicados. Sin duda todos ellos, unos y otros, fueron necesarios. 